Received Date: 01-Dec-2014

Revised Date: 15-Jun-2015

Accepted Date: 17-Aug-2015

Article Type: Reports

MS 14-2298

\title{
Report \\ Evidence and population consequences of shared larval dispersal histories in a marine fish
}

Shared larval dispersal histories

Jeffrey S. Shima', ${ }^{1,3}$ and Stephen E. Swearer ${ }^{2}$

${ }^{1}$ School of Biological Sciences, Victoria University of Wellington, P.O. Box 600, Wellington 6140 New Zealand

${ }^{2}$ Department of Zoology, University of Melbourne, Melbourne, Victoria 3010 Australia

Manuscript received 1 December 2014; revised 15 June 2015; accepted 17 August 2015.

Corresponding Editor: J. R. Rooker.

${ }^{3}$ E-mail: jeffrey.shima@vuw.ac.nz

Abstract.

Larval dispersal is disproportionately important for marine population ecology and evolution, yet our inability to track individuals severely constrains our understanding of this key process. We analyze otoliths of a small reef fish, the common triplefin (Forsterygion lapillum), to reconstruct individual dispersal histories and address the following questions: (1) How many discrete sets of dispersal histories (dispersal cohorts) contribute to replenishment of focal populations; (2) When do dispersal cohorts converge (a metric of shared dispersal histories This is the author manuscript accepted for publication and has undergone full peer review but has not been through the copyediting, typesetting, pagination and proofreading process, which may lead to differences between this version and the Version of Record. Please cite this article as doi: $\underline{10.1002 / \text { ecy.1204 }}$

This article is protected by copyright. All rights reserved 
among cohorts); and (3) Do these patterns predict spatiotemporal variation in larval supply? We used light traps to quantify larval supply, and otolith microstructure and microchemistry (using laser ablation inductively coupled plasma mass spectrometry; LA-ICP-MS) to reconstruct daily environmental histories of individuals in their 30-d lead-up to settlement. Our results indicate that a variable number of dispersal cohorts replenish focal populations (range of 2-8, mean of 4.3 , standard deviation of 2.8). Convergence times varied (from 0 to $>30 \mathrm{~d}$ prior to settlement), and larval supply was negatively correlated with cohort evenness but not with the number of cohorts, or when they converged, indicating disproportionately large contributions from some cohorts (i.e., sweepstakes events). Collectively, our results suggest that larval reef fishes may variably disperse in shoals, to drive local replenishment and connectivity within a metapopulation.

Key words:

common triplefin; connectivity; developmental history; dispersal cohorts; Forsterygion lapillum; larval packets; shared dispersal history.

\section{Introduction}

Many plants and animals are relatively sedentary as adults, but produce large numbers of offspring (i.e., seeds, spores, eggs, and/or larvae) that can disperse over variable distances before establishment, with important consequences for species distributions, population dynamics, and evolutionary processes (Turchin 1998, Clobert et al. 2001). Quantifying dispersal, however, can be difficult (Ims and Yoccoz 1997, Swearer et al. 2002, Nathan et al. 2003), as telemetric and related approaches that are useful for tracking large-bodied animals cannot be feasibly applied to seeds, spores, eggs, or larvae because of their small size. Genetic, isotopic, and chemical tags have been used effectively for small dispersers (e.g., Godoy and Jordano 2001, Jones et al. 2005, Carlo et al. 2013), but these methods are generally unable to resolve the dispersal histories (i.e., trajectories through space) of individuals beyond their starting and ending points.

Identifying sources and destinations of dispersers is important for characterizing patterns of connectivity that can shape metapopulation dynamics and gene flow. However, a growing body of empirical evidence and theory suggests that an understanding of dispersal histories may be necessary to resolve some of the underlying mechanisms of realized connectivity (i.e., postdispersal survival to reproductive age; Shima and Swearer 2009a, Burgess et al. 2012). Our own 
work on a small reef fish, the common triplefin (Forsterygion lapillum), suggests that variation in larval dispersal histories can have significant demographic consequences by affecting the number (Shima and Swearer 2009b, Swearer and Shima 2010) and phenotypes (Shima and Swearer 2009a) of fish that replenish local populations, with flow-on effects to juvenile growth and condition (Shima et al. 2015), survival to adulthood (Shima and Swearer 2010), population stability (Noonburg et al. 2015), and metapopulation persistence (Shima et al. 2015).

A number of important questions about marine larval dispersal, however, remain unresolved. Notably, are dispersal histories variable or shared among individuals (which may influence the distribution of phenotypes, and associated demographic consequences)? Variable dispersal histories may arise from random walk movements of individuals, or from diffusive hydrodynamic conditions. Shared dispersal histories may result from the behavior of dispersers (e.g., shoaling) or eddy features that aggregate and transport dispersers together (e.g., Shulzitski et al. 2015). Shared dispersal histories are indirectly suggested by genetic evidence for concurrent settlement of full siblings to the same location (e.g., Selkoe et al. 2006, Bernardi et al. 2012). Such studies typically, however, can only confirm common start- and endpoints of dispersal (and only for the most extreme cases involving genetically related individuals). Our previous results for the common triplefin suggest that the journey matters, independent of common origin (Shima and Swearer 2009a).

The difficulties of tracking marine larvae mean we have almost no information about the degree of shared vs. divergent dispersal histories, or their demographic consequences. Many particle-tracking models attempt to reconstruct individual dispersal trajectories of marine larvae, but those results are highly sensitive to diffusivity estimates and larval behavior, which are both often poorly resolved (Siegel et al. 2008, Snyder et al. 2014).

Here, we evaluate environmental chronologies recorded in the otoliths of fish larvae, to reconstruct dispersal histories of sets of individuals that replenish focal populations on the same night. We implement a range of multivariate techniques to extract information from these otolith records to evaluate: (1) evidence for shared vs. divergent dispersal histories, (2) the number of distinct dispersal histories that replenish local populations, (3) the timing of their convergence, and (4) the characteristics of dispersal histories that may explain variation in replenishment.

\section{Methods}

This article is protected by copyright. All rights reserved 


\section{Study system and sampling}

We estimated patterns and consequences of shared dispersal histories for the common triplefin (Forsterygion lapillum), a widely distributed and abundant rocky reef fish in New Zealand (Wellenreuther et al. 2007). Adults are site attached (Shima et al. 2012), but produce pelagic larvae (larval duration $~ 52$ d; Shima and Swearer 2009a, $b$ ) before settling back to rocky reefs. Variation in dispersal history shapes the phenotypes of settling fish (Shima and Swearer $2009 a$ ) and their probabilities of surviving to adulthood (Shima and Swearer 2010). We provide detailed descriptions of our methods in Appendices A-C.

Briefly, we used light traps (e.g., Hickford and Schiel 1999) to sample late-stage larvae at five sites along the eastern shore of Kapiti Island $\left(40.8667^{\circ} \mathrm{S}, 174.9000^{\circ} \mathrm{E}\right)$ over a series of nights in austral summer, 2008 (Fig. 1a, b; see Appendix A for details). Three traps ( $\sim 60 \mathrm{~m}$ apart) were deployed $\sim 50 \mathrm{~m}$ from rocky reefs at each site, and catches were pooled within sites for all subsequent analyses. We quantified larval supply as the total catch of larval $F$. lapillum for each site on a given night, and we randomly subsampled this catch to characterize the dispersal histories of individuals. We constrained our analysis to site-date combinations that had $\geq 10$ subsampled individuals ( $n=9$ site-date observations; see Appendix B).

\section{Characterizing individual dispersal histories}

Using sagittal otoliths (Fig. 1c) from 118 individuals, we quantified daily growth history (using otolith microstructure) and trace element concentrations (using laser ablation inductively coupled plasma mass spectrometry; LA-ICP-MS) following Shima and Swearer (2009a; see also Appendix B). Growth histories allowed us to reconstruct daily trace element concentrations (i.e., putative environmental signatures). For each fish, we evaluated time-series of 12 trace elements ( $\mathrm{Li}, \mathrm{B}, \mathrm{Mg}, \mathrm{P}, \mathrm{S}, \mathrm{K}, \mathrm{Mn}, \mathrm{Cu}, \mathrm{Zn}, \mathrm{Sr}, \mathrm{Ba}, \mathrm{Pb}$ ) in reverse chronological order (i.e., as hindcasts), from otolith edge (day of collection) to core (day of hatch; Fig. 1b,c). Our approach assumes that variation in trace element concentrations recorded within otoliths reflects spatiotemporal variation in the environment (e.g., water masses with different physicochemical properties).

We identified a subset of seven elements ( $\mathrm{Mg}, \mathrm{P}, \mathrm{K}, \mathrm{Mn}, \mathrm{Sr}, \mathrm{Ba}, \mathrm{Pb})$ based on their ability to reconstruct hindcasted variation in the pelagic environment (i.e., a geographic signature, see Appendix $\mathrm{C}$ for details of the screening process). Using this subset, we calculated 13 statistical descriptors that characterized the hindcasted time series of each element (i.e., a

This article is protected by copyright. All rights reserved 
pelagic duration of $\sim 30$ consecutive days preceding collection) for each sampled individual (following methods of Wang et al. 2006, Shima and Swearer 2009a), yielding a set of 91 variables to characterize each individual dispersal history. We used a principal components analysis to reduce the dimensionality of this set to nine principal components (the most that could be accommodated by a subsequent clustering approach given our sample size; the first nine principal components accounted for $45 \%$ of the variation in the full data set). We used the first nine principal component scores to cluster fish (separately for each site-date observation) that had similar environmental histories during the same $\sim 30-\mathrm{d}$ period (hereafter, cohorts). Clustering was performed with a $K$-means algorithm (using JMP v10.0; SAS Institute, Cary, North Carolina, USA), and the cubic clustering criterion (CCC) was used to determine the most likely number of dispersal cohorts comprising each site-date observation. The existence of dispersal cohorts was interpreted as evidence of shared dispersal histories among individual fish.

\section{Dispersal trajectories of cohorts}

We estimated dispersal trajectories of identified cohorts in multivariate space, and assumed these trajectories to be a proxy for movement in geographic space. This approach facilitated visualization of dispersal trajectories for each cohort, and enabled us to estimate cohort convergence times. For each site-date observation, we conducted a canonical discriminant analysis (PROC CANDISC, SAS v9.3; SAS Institute), using daily concentrations of the seven trace elements most likely to be proxies of geographic location (see Appendix C). We visualized dispersal trajectories of each cohort with plots of their mean canonical scores for successive days prior to collection, for the first two canonical variables (i.e., plots of CAN2 vs. CAN1). In order to objectively evaluate the convergence times of cohorts (e.g., interpreted as evidence of arrival in similar water masses), we generated a data matrix of squared Mahalanobis distances between cohort means (a standard statistical output of a canonical discriminant analysis) for each day prior to collection (up to $30 \mathrm{~d}$ ). The canonical discriminant analysis also generates a corresponding matrix of one-way analysis of variance tests, which evaluate the null hypothesis that cohort means on given days were equal (i.e., in the same canonical space; see Supplement). This statistical output (given in Supplement) enabled us to calculate the proportion of time that dispersal trajectories shared similar environmental histories (i.e., $P \geq 0.05$; hereafter, proportional convergence). Additionally, for each site-date, we defined a convergence time (i.e., a point in time when two dispersal trajectories begin to consistently share a similar This article is protected by copyright. All rights reserved 
environmental history as they approached a common collection site). To determine convergence time, we started at the endpoint of a dispersal trajectory (date of collection) and followed a pair of trajectories back in time and identified the first point of bifurcation (which we defined as the first instance prior to collection with $\geq 3$ consecutive days of divergent environmental signatures; $P<0.05$ for the difference between cohort means). We estimated a mean convergence time for each site-date observation as the mean of all pairwise comparisons.

Lastly, to further characterize spatiotemporal variation in the composition of dispersal trajectories, we calculated metrics of cohort diversity for each site-date observation. Specifically, we estimated cohort richness, the number of cohorts (i.e., clusters) that contributed to larval supply, and cohort evenness using Pielou's evenness index, where low evenness indicates some cohorts contribute more to larval supply than others.

Consequences of variable dispersal trajectories

We evaluated whether larval supply is determined (at least in part) by aspects of dispersal histories. Specifically, we hypothesized that larval supply could be predicted by some combination of: (1) cohort richness (e.g., recruitment increases with accumulation of cohorts with different dispersal trajectories); (2) cohort evenness (e.g., recruitment increases with disproportionate contributions from specific dispersal trajectories); (3) proportional convergence (e.g., recruitment increases as cohorts share more of their dispersal trajectories); and/or (4) mean convergence time (e.g., recruitment increases with earlier convergence/accumulation at the recruitment site). We explored support for these (non-mutually exclusive) hypotheses using stepwise multiple regression (the dependent variable, larval supply was log-transformed to meet assumptions of this test; analyses conducted in SAS v9.3).

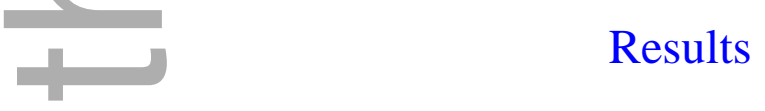

Dispersal trajectories of cohorts

$K$-means clustering identified a variable number of dispersal cohorts (mean $=4.3$, standard deviation $=2.8$, range $=2-8$ ) that replenished nine site-date observations. Trajectories of cohorts in canonical space (a proxy for geographic space) showed a range of patterns (Fig. 2). Larval supply at site 1 on 14 January 2008 (Fig. 2a) consisted of 25 individuals that were unevenly distributed between two dispersal cohorts with no evidence of convergence in their

This article is protected by copyright. All rights reserved 
approach to the collection site (convergence time $=0$, proportional convergence $=0.03$; the Supplement gives statistical comparisons that underlie inferences of convergence for all site-date observations). This pattern suggests that the two cohorts (Fig. 2a) experienced very different pelagic environments for the $30 \mathrm{~d}$ preceding collection, and entered a common environment only upon their arrival to light traps. Site 5 was sampled on the same night, and larval supply (225 fish) was unevenly distributed among three dispersal cohorts that had a mean convergence time of $21.3 \mathrm{~d}$ prior to collection and a proportional convergence of 0.79 (Fig. 2b). Larval supply to site 4 on 10 February 2008 (Fig. 2f) was divided fairly evenly between four cohorts that, collectively, showed convergent environmental signatures from $5 \mathrm{~d}$ prior to settlement. However, two distinct convergence patterns are clearly evident in the dispersal trajectories for this site date (Fig. 2f). Larval supply to site 3 on 10 February 2008 was roughly evenly distributed among eight dispersal cohorts, with one of these cohorts showing extremely divergent environmental signatures early in its trajectory toward the collection site (Fig. 2e). The outlier cohort in this panel obscures the variation in canonical space of the remaining seven cohorts (which is evident and similar in magnitude to the other panels when this cohort is excluded from the plot). Two other site-date observations (Fig. 2d, h) were also characterized by larval supply distributed approximately evenly among eight dispersal cohorts, with some cohorts showing signs of convergence in their approach to the collection site, and others not. For three other site-date observations, (Fig. 2c, g, i) larval supply varied from 20 to 1120 individuals, but in all cases supply was unevenly distributed between two dispersal cohorts that had convergent environmental signatures for most/all of the 30-d period prior to collection. Consequences of variable dispersal trajectories

Variation in log-transformed larval supply was explained by cohort evenness $\left(F_{1,7}=7.39\right.$, $P=0.03, R^{2}=0.51$; Fig. 3 ), but not by cohort richness, or by proportional convergence or mean convergence time of dispersal cohorts (which were not retained in the stepwise model; further analyses confirmed that, when modeled separately, only cohort evenness was a significant predictor of Tarval supply). The number of fish captured by light traps declined exponentially with cohort evenness, indicating that replenishment appears to increase with disproportionately large contributions from a small number of dispersal cohorts (as opposed to by an accumulation of many dispersal cohorts).

This article is protected by copyright. All rights reserved 


\section{Discussion}

Knowledge of dispersal histories is essential for understanding the dynamics of spatially structured populations (e.g., Shima et al. 2010). Using reconstructed environmental chronologies from the otoliths of larval fish, we found evidence for complex and variable patterns of larval dispersal. This is likely to have important ecological consequences for triplefin populations as dispersal pathways can have demographic consequences that are immediate (e.g., affecting growth and survival during dispersal), and/or that manifest after dispersal is complete (e.g., affecting future condition, growth, or survival at the destination site; Stamps et al. 2005, Burgess et al. 2012, Shima et al. 2015).

Based upon the hydrodynamic context for our study, we had a priori reasons to suspect variable patterns of larval dispersal among sites and dates. The hydrodynamic setting for Kapiti Island and the greater Cook Strait is characterized by strong, tidally driven currents that interact with coastline features and bathymetry to produce complex circulation and eddy fields (Chiswell and Stevens 2010). We hypothesized that such eddies might aggregate larvae (potentially at the natal site, or at some point further along a dispersal trajectory) and then transport them as a group to their destination site. Because our previous work suggested that shared dispersal histories might have strong effects on a wide range of demographic parameters (see Introduction), we wished to better understand patterns of dispersal (e.g., how many dispersal cohorts characterize larval supply, and when do they form) and the potential consequences of this variation.

We adopted a forensic approach that enabled us to reconstruct (and visualize) dispersal trajectories in canonical space. Fig. 2 suggests at least three general patterns of incoming trajectories of dispersers: (1) multiple cohorts that were convergent in their environmental signatures for an extended period of time (Fig. 2c, g, i); (2) cohorts that, on average, converged near the settlement site $\sim 5 \mathrm{~d}$ prior collection (Fig. $2 \mathrm{~d}-\mathrm{f}, \mathrm{h}$ ); and (3) cohorts that never converged (Fig. 2a). If we assume that canonical space is a proxy for geographic space, then the first of these patterns implies groups of individuals might be traveling together from as far back as their natal sites (as exemplified in Fig. 1bii; see also Selkoe et al. 2006, Bernardi et al. 2012). The second of these patterns suggests that larval fish may accumulate (perhaps near reefs) prior to settlement (e.g., Fig. 1bi-iii; see also Warner et al. 2000) and this is consistent with our own observations of shoals of pre-competent fish larvae on or adjacent to reefs (J. Shima, personal 
observation), and with other recent published accounts (Beldade et al. 2006). The third general pattern (no convergence, Fig. 1i vs. iv) suggests that recruitment events may occasionally comprise cohorts that had different dispersal trajectories for their entire larval duration, and converged to a common environment for the first time in a light trap (leaving insufficient time for this to be recorded in a final otolith increment). Such individuals could have arrived at different times over the course of the night (e.g., in different eddies that had different environmental signatures, and potentially, different origins), and indeed, the occurrence of different convergence patterns for subsets of cohorts for several site-date observations (e.g., Fig. $2 \mathrm{f}$, and to a lesser degree, $\mathrm{d}$ and $\mathrm{h}$ ) are consistent with this hypothesis.

We evaluated the potential consequences of spatiotemporal heterogeneity in dispersal histories, and found that the magnitude of larval supply was negatively correlated with the degree of evenness (in terms of apportionment of larvae) among the three cohorts. Hence, larval supply was greatest when larvae were unevenly distributed (i.e., one cohort was more commonly represented than all others). We believe this suggests that large recruitment events may be driven (at least in part) by groups of fish that share a particular dispersal history as opposed to groups of fish that accumulate near a settlement site, or by a confluence of many different dispersal histories. Our results are consistent with a sweepstakes hypothesis, where the lucky cohort accumulates in a favorable developmental conditions, giving increased chances of survival to settlement. Sweepstakes events in this context may be facilitated by behavior patterns of dispersers (e.g., shoaling) and/or aggregation in hydrodynamic features (e.g., eddies; Shulzitski et al. 2015), and likely have important consequences for patterns of connectivity (i.e., reduced variation in dispersal patterns among individuals from a common origin). Moreover, cohorts of common triplefin that share developmental histories and settle together are likely to share phenotypes (Shima and Swearer 2009a), which potentially affects population dynamics via effects on intraspecific competition (e.g., Noonburg et al. 2015, Shima et al. 2015).

In summary, our results provide support for shared dispersal histories among larval reef fish that replenish local populations. Evidence for this is provided by the initial detection of cohorts (i.e., groups of fish that share common environmental histories) and by the convergence patterns of cohorts themselves. Nearly half of all site-date observations (four of nine) were comprised of cohorts experiencing similar environmental conditions for $>75 \%$ of the sampled larval period. Most of the remaining observations (four of nine) were consistent with larval This article is protected by copyright. All rights reserved 
accumulation events that occurred $\sim 5 \mathrm{~d}$ prior to collection, while one observation suggested no accumulation period prior to collection. Collectively, these findings indicate substantial heterogeneity in dispersal histories that correlates with larval supply and may have additional implications for the dynamics of marine populations via fitness costs that may be manifested long after settlement.

Acknowledgments

Funding was provided by two Marsden grants (to J. Shima, S. Swearer, and S. Chiswell; and to J. Shima, S. Swearer, and E. Noonburg). Research assistance was provided by D. McNaughtan, D. Aguirre-Davies, L. Liggins, P. Neubauer, J. Oliver, A. Perez-Matus, and J. Ford. Logistical assistance was provided by the Victoria University Coastal Ecology Lab.
(2)
Literature Cited

Beldade, R., R. Borges, and E. J. Goncalves. 2006. Depth distribution of nearshore temperate fish larval assemblages near rocky substrates. Journal of Plankton Research 28:10031013

Bernardi, G., R.Beldade, S. J. Holbrook, and R. J. Schmitt. 2012. Full-sibs in cohorts of newly settled coral reef fishes. PLoS ONE 7(9):e44953.

Burgess, S. C., E. A. Treml, and D. J. Marshall. 2012. How do dispersal costs and habitat selection influence realized population connectivity? Ecology 93:1378-1387.

Carlo, T. A., D. Garcia, D. Martinez, J. M. Gleditsch, and J. M. Morales. 2013. Where do seeds go when they go far? Distance and directionality of avian seed dispersal in heterogeneous landscapes. Ecology 94:301-307.

Chiswell, S. M., and C. L. Stevens. 2010. Lagrangian and Eulerian estimates of circulation in the lee of Kapiti Island, New Zealand. Continental Shelf Research 30:515-532.

Clobert, J.,E. Danchin, A. A. Dhondt, and J. D. Nichols, editors. 2001. Dispersal. Oxford University Press, Oxford, UK.

Godoy, J. A., and P. Jordano. 2001. Seed dispersal by animals: exact identification of source trees with endocarp DNA microsatellites. Molecular Ecology 10:2275-2283.

Hickford, M. J. H., and D. R. Schiel. 1999. Evaluation of the performance of light traps for sampling fish larvae in inshore temperate waters. Marine Ecology Progress Series 186:293-302.

This article is protected by copyright. All rights reserved 
Ims, R. A., and N. G. Yoccoz. 1997. Studying transfer processes in metapopulations: emigration, migration, and colonization. Pages 247-265 in I. A. Hanski and M. E. Gilpin, editors. Metapopulation biology: ecology, genetics, and evolution. Academic Press, London, UK.

Jones, G. P., S. Planes, and S. R. Thorrold. 2005. Coral reef fish settle close to home. Current Biology 15:1314-1318.

Nathan, R., G. Perry, J. T. Cronin, A. E. Strand, and M. L. Cain. 2003. Methods for estimating long-distance dispersal. Oikos 103:261-273.

Noonburg, E. K., A. Chen, J. S. Shima, and S. E. Swearer. 2015. Demographic heterogeneity and the dynamics of open populations. Ecology 96:1159-1165.

Selkoe, K. A., S. D. Gaines, J. E. Caselle, and R. R. Warner. 2006. Current shifts and kin aggregation explain genetic patchiness in fish recruits. Ecology 87:3082-3094.

Shima, J. S., D. McNaughtan, S. W. Geange, and S. Wilkinson. 2012. Ontogenetic variation in site fidelity and homing behaviour of a temperate reef fish. Journal of Experimental Marine Biology and Ecology 416-417:162-167.

Shima, J. S., E. G. Noonburg, and N. E. Phillips. 2010. Larval dispersal in spatially structured coastal environments; life history and matrix heterogeneity interact to shape connectivity in marine metapopulations. Ecology 91:1215-1224.

Shima, J. S., E. G. Noonburg, and S. E. Swearer. 2015. Consequences of variable larval dispersal pathways and resulting phenotypic mixtures to the dynamics of marine metapopulations. Biology Letters 11:20140778.

Shima, J. S., and S. E. Swearer. 2009a. Larval quality is shaped by matrix effects: implications for connectivity in a marine metapopulation. Ecology 90:1255-1267.

Shima, J. S., and S. E. Swearer. 2009b. Spatially variable larval histories may shape recruitment rates of a temperate reef fish. Marine Ecology Progress Series 394:223-229.

Shima, J. S., and S. E. Swearer. 2010. The legacy of dispersal: larval experience shapes persistence later in the life of a reef fish. Journal of Animal Ecology 79:1308-1314.

Shulzitski, K., S. Sponaugle, M. Hauff, K. Walter, E. K. D’Alessandro, and R. K. Cowen. 2015. Close encounters with eddies: oceanographic features increase growth of larval reef fishes during their journey to the reef. Biology Letters 11:20140746. 
Siegel, D. A., S. Mitarai, C. J. Costello, S. D. Gaines, B. E. Kendall, R. R. Warner, and K. B. Winters. 2008. The stochastic nature of larval connectivity among nearshore marine populations. Proceedings of the National Academy of Sciences USA 105:8974-8979.

Snyder, R. E., C. B. Paris, and A. C. Vaz. 2014. How much do marine connectivity fluctuations matter? American Naturalist 184:523-530.

Stamps, J. A., V.V. Krishnan, and M. L. Reid. 2005. Search costs and habitat selection by dispersers. Ecology 86:510-518.

Swearer, S. E., and J. S. Shima. 2010. Regional variation in larval retention and dispersal drives recruitment patterns in a temperate reef fish. Marine Ecology Progress Series 417:229_ 236.

Swearer, S. E., J. S. Shima, M. E. Hellberg, S. R. Thorrold, G. P. Jones, D. R. Robertson, S. G. Morgan, K. A. Selkoe, G. M. Ruiz, and R. R. Warner. 2002. Evidence of self-recruitment in demersal marine populations. Bulletin of Marine Science 70:251-271.

Turchin, P.1998. Quantitative analysis of movement. Sinauer, Sunderland, Massachusetts, USA. Wang, X., K. Smith, and R. Hyndman. 2006. Characteristic based clustering for time series data. Data Mining and Knowledge Discovery 13:335-364.

Warner, R. R., S. E. Swearer, and J. E. Caselle. 2000. Larval accumulation and retention: implieations for the design of marine reserves and essential fish habitat. Bulletin of Marine Science 66:821-830.

Wellenreuther, M., P. T. Barrett, and K. D. Clements. 2007. Ecological diversification in habitat use by subtidal triplefin fishes (Tripterygiidae). Marine Ecology Progress Series $330: 235-246$.

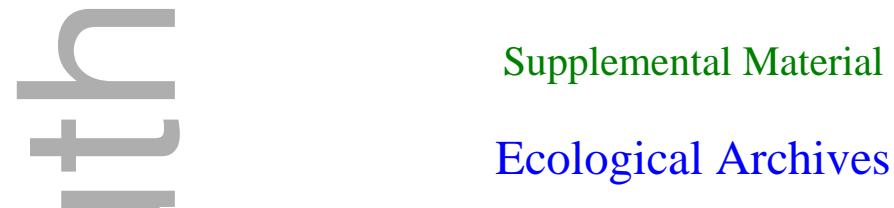

Appendices A-C and the Supplement are available online: http://dx.doi.org/10.1890/142298.1.sm

Fig. 1. Evaluating evidence for shared dispersal histories. (a) Inset showing location of Kapiti Island, New Zealand, where (b) we estimated larval supply of a small reef fish, the common triplefin (Forsterygion lapillum), with light traps $(n=3)$ at each of five sites (yellow diamonds) over several nights. For each site-date observation $(n=9)$, we reconstructed the daily 
environmental histories of individuals in reverse chronological order (i.e., hindcasted time, spanning $\sim 30 \mathrm{~d}$, illustrated by the orange arrows). Four hypothetical trajectories are shown for dispersal cohorts (i.e., groups of fish with similar environmental signatures) that were collected at site 2 on the same night: (i) and (iv) illustrate unshared dispersal histories; (ii) illustrates fully shared dispersal histories, and (iii) illustrates a dispersal history that is partially shared with (ii). (c) The inset shows a sampled otolith and the reverse chronological ordering that gives information about daily variation in microchemistry concentrations (e.g., dispersal trajectories in canonical space; Fig. 2), and we assume this corresponds to geographic space.

Fig. 2. Trajectories of dispersal cohorts in canonical space (both axes show canonical scores; CAN1 and CAN2) for nine site-date observations (panels a-i). Dispersal cohorts are represented by different colors. Daily trajectories (lines connecting dots) begin $30 \mathrm{~d}$ prior to collection $(<30 \mathrm{~d}$ in some instances where cohorts were comprised of younger individuals) and end upon arrival to the collection site (yellow diamonds). Larval supply is given at the bottom of each frame; mean convergence time (CT) and proportional convergence (PC) are given at the top. Stacked bars give the proportion of larval supply comprised by each dispersal cohort (evenness; colors correspond to trajectories).

Fig. 3. Larval supply (total catch of larval F. lapillum per site on a given night) declines exponentially with cohort evenness $\left(P=0.03, R^{2}=0.51\right.$; the back-transformed regression line (solid) and $95 \%$ confidence intervals for this relationship (dotted lines) are given.

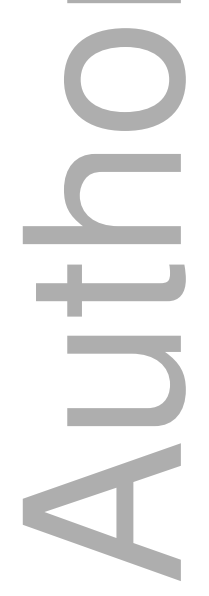




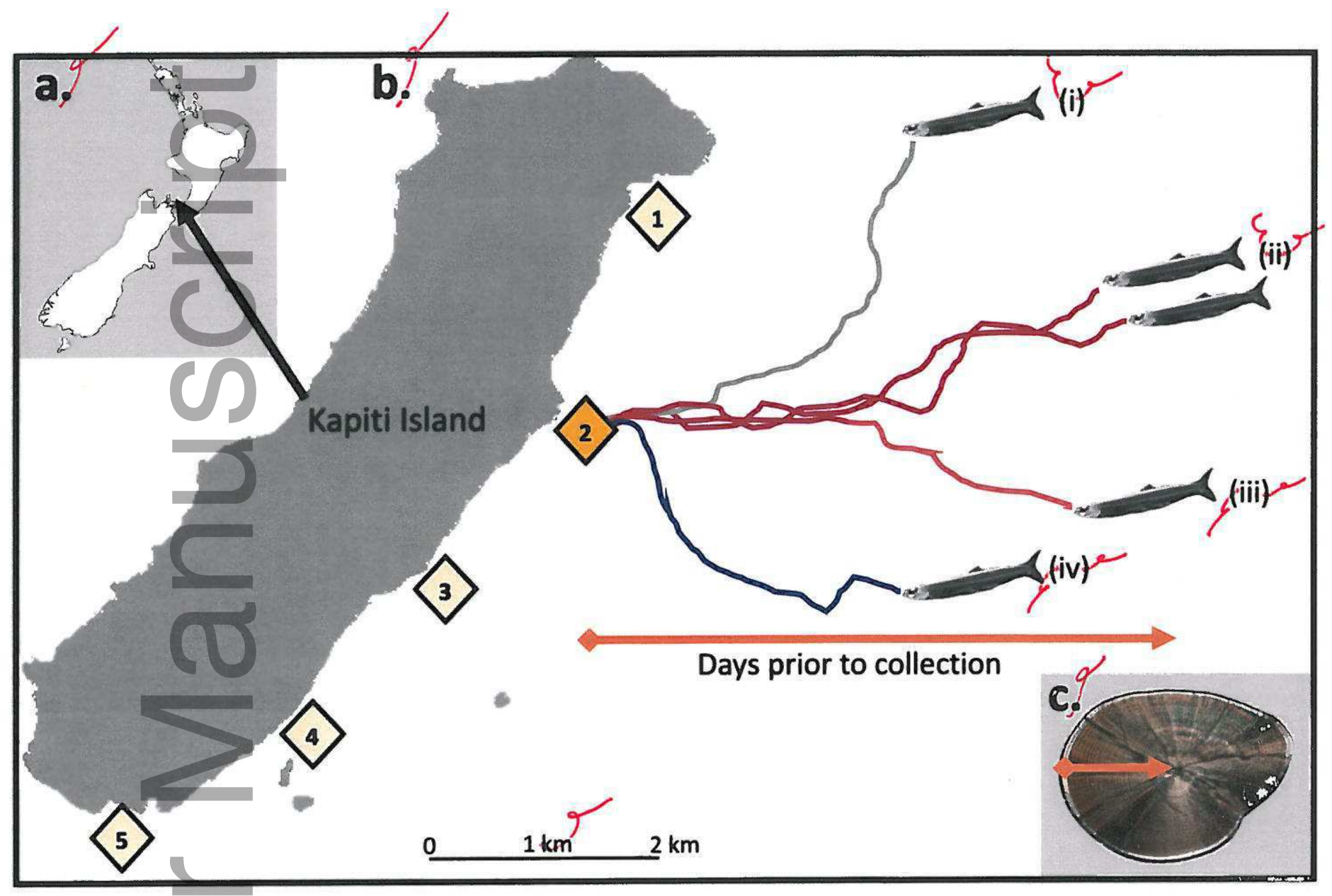

389

390

\section{color: no charge}

(reports macro)

This article is protected by copyright. All rights reserved 
391 Figure 2

392

Shima $14-2298$ fig 2
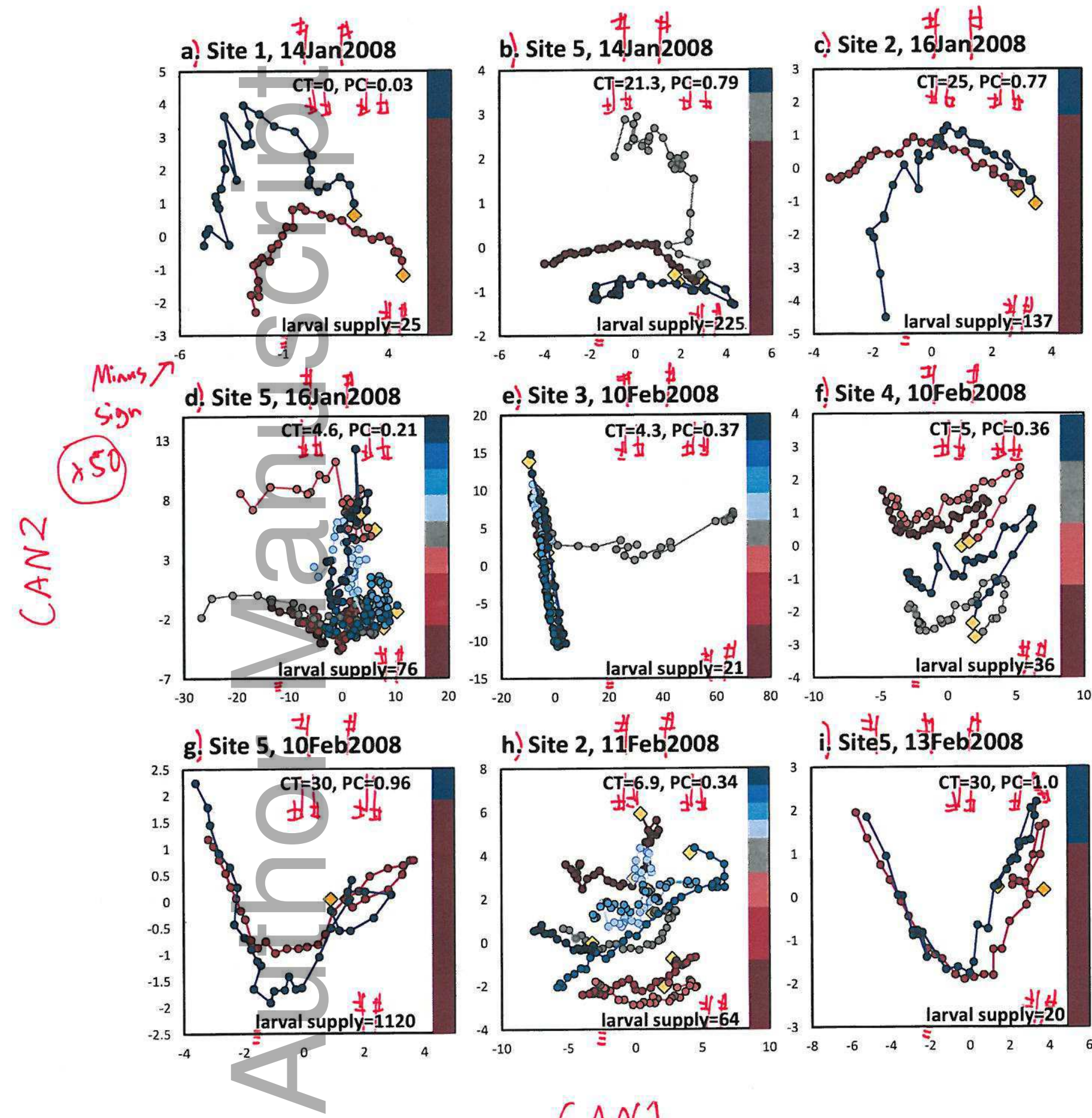

h) Site 2, 11/Feb?2008

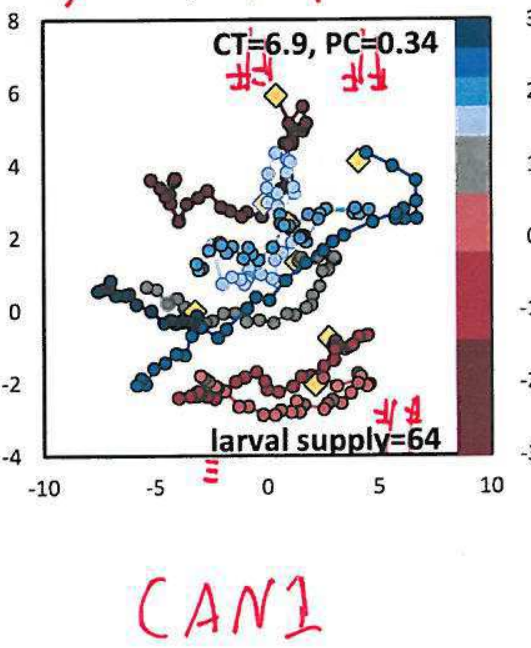

i) Sitẹ 5,13 Feb2008

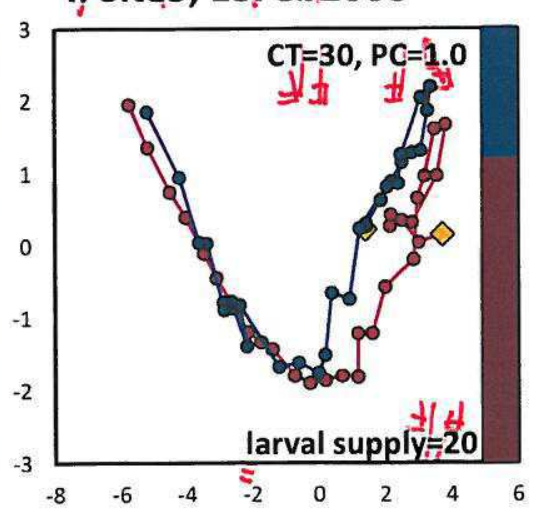


394

395

396

397

398

399

400

401

402

Figure 3

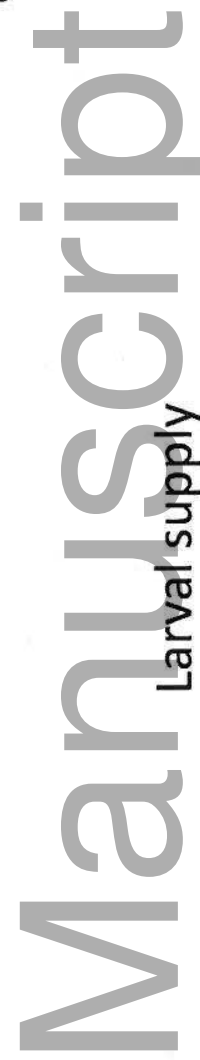

1500

900

600

300

0

\begin{abstract}
0.5
\end{abstract}

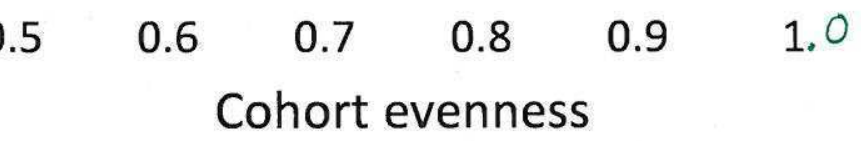

21

This article is protected by copyright. All rights reserved 


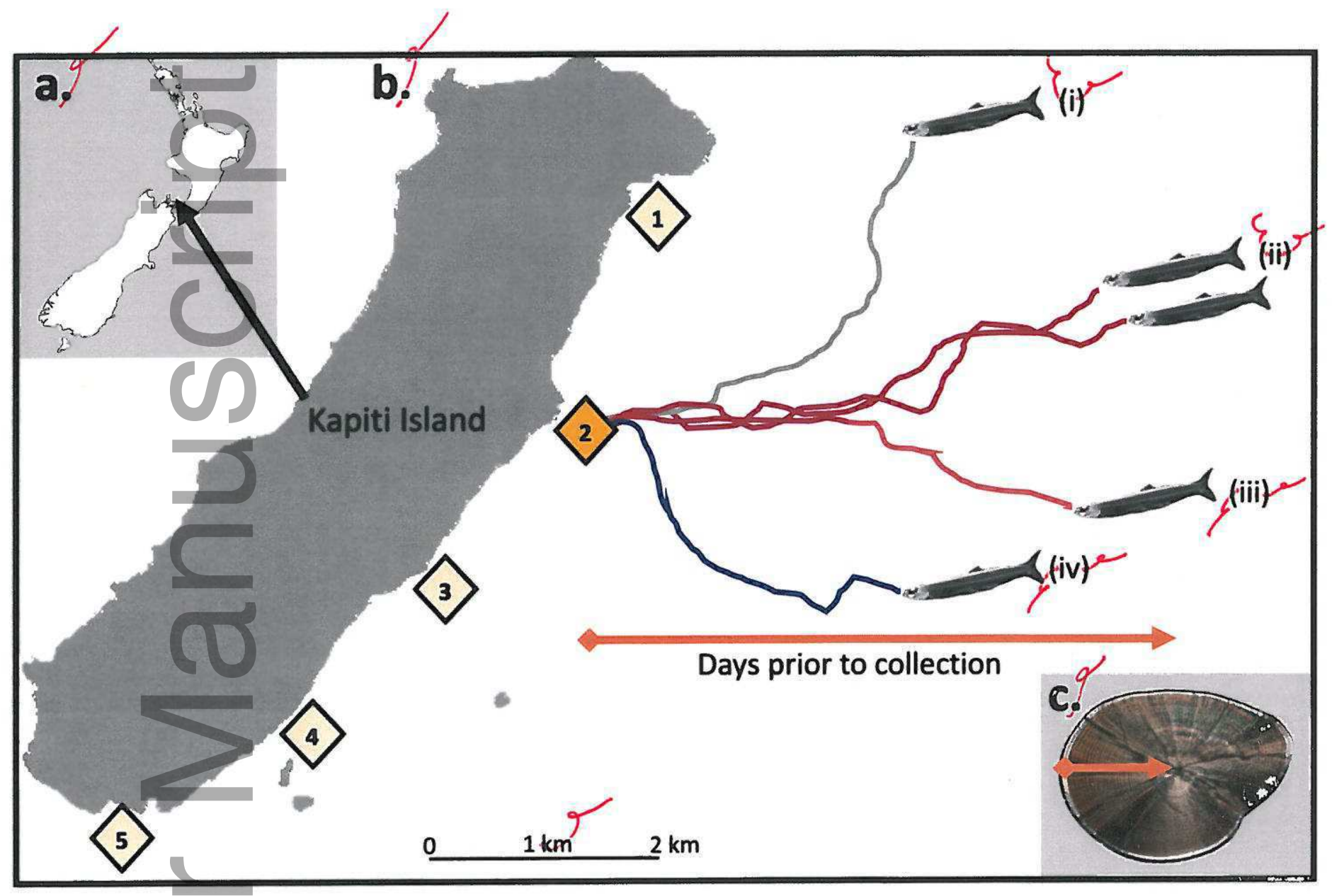

389

390

\section{color: no charge}

(reports macro)

This article is protected by copyright. All rights reserved 
391 Figure 2

392

Shima $14-2298$ fig 2
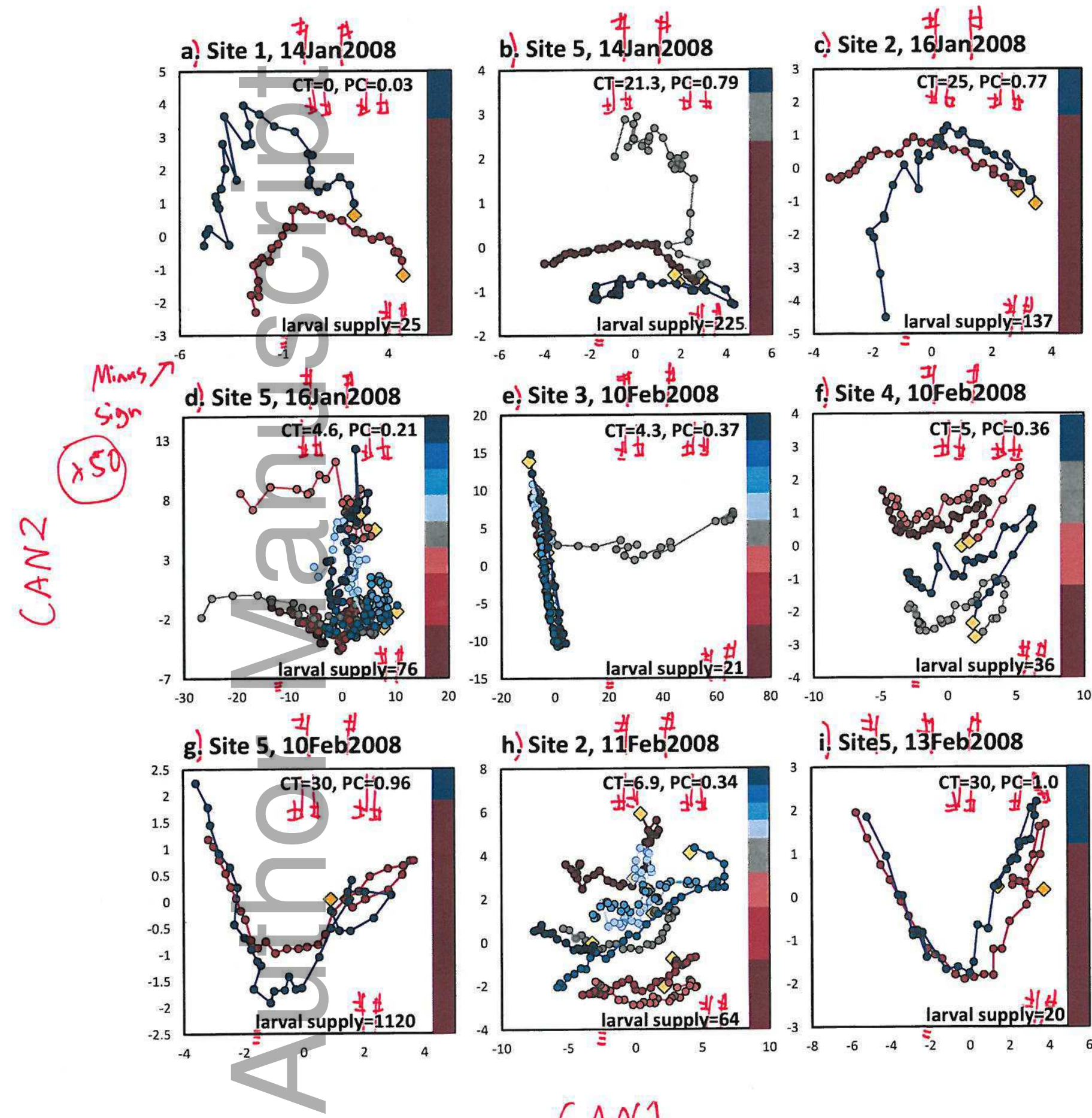

h) Site 2, 11/Feb?2008

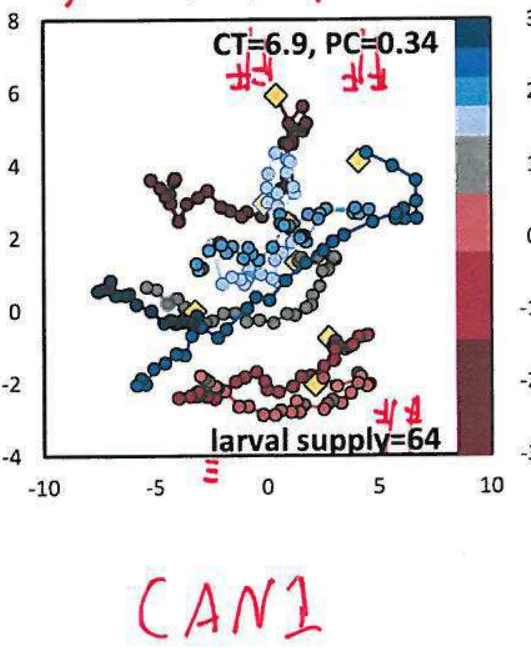

i) Sitẹ 5,13 Feb2008

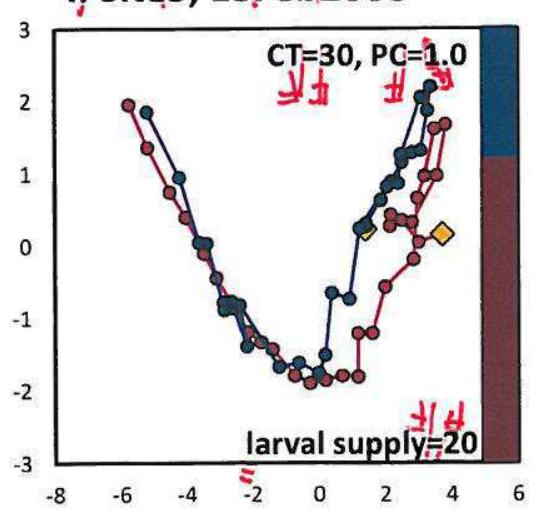


394

395

396

397

398

399

400

401

402

Figure 3

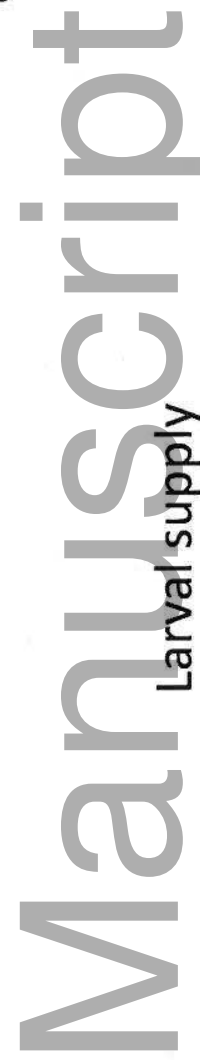

1500

900

600

300

0

\begin{abstract}
0.5
\end{abstract}

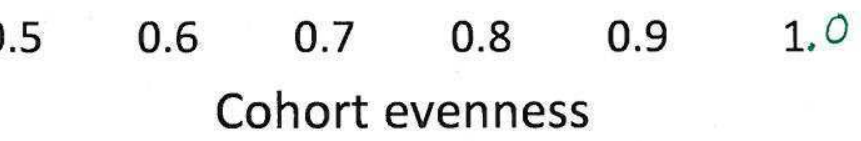

21

This article is protected by copyright. All rights reserved 


\section{University Library}

\section{- M M I N E R VA A gateway to Melbourne's research publications}

Minerva Access is the Institutional Repository of The University of Melbourne

Author/s:

Shima, JS;Swearer, SE

Title:

Evidence and population consequences of shared larval dispersal histories in a marine fish

Date:

2016-01-01

Citation:

Shima, J. S. \& Swearer, S. E. (2016). Evidence and population consequences of shared larval dispersal histories in a marine fish. ECOLOGY, 97 (1), pp.25-31. https:// doi.org/10.1890/14-2298.1.

Persistent Link:

http://hdl.handle.net/11343/290771 